TECHNICAL REPORT

December 1 through February 28, 1993

\author{
Project Title: EVALUATION AND UTILIzATION OF ILLINOIS FBC \\ RESIDUES FOR CONSTROCTION MATERIALS \\ DE-FC2292PC 92521 \\ Principal Investigator: N. Ghafoori \\ Department of Civil Engineering and \\ Mechanics \\ Southern Illinois University \\ at Carbondale \\ Carbondale, Illinois 62901 \\ 618-453-7810 \\ Other Investigator: \\ S. Sami \\ Department of Civil Engineering and \\ Mechanics \\ Southern Illinois University \\ at Carbondale \\ Carbondale, Illinois 62901 \\ 618-453-7815 \\ Project Manager: \\ Dan Banerjee, Illinois Clean Coal \\ Institute
}

\title{
ABSTRACT
}

The overall objective of this program is to investigate the extent to which fluidized bed combustion (FBC) by-products can be properly utilized as viable construction materials. This investigation focuses primarily on the properties of residues derived from fluidized combustion burning of Illinois high-sulfur coal. The research plan calls for evaluation of physico-chemical and engineering characteristics of the FBC-based cement and non-cement mixes. The results of this study will be used to compare the physical and mechanical properties of the FBC-based mixtures with those of conventional mixes. The results of this study will be used to compare the physical and mechanical properties of the FBC-based mixtures with those of conventional mixes. The suitability of using FBC residues as filler or binder aggregates for Portland cement-based mixtures and nonPortland cement mixes in the form of conventional and roller compacted materials will be evaluated.

During this reporting period, laboratory specimens relevant to the final phase of this research program; engineering characteristics of the optimized FBC spent bed and Ely ash concretes (Task I), and engineering properties of the optimized roller compacted non-cement FBC mixes (Task II); were fabricated. Tests on fresh and hardened properties are ongoing. 


\section{EXECOTIVE SUMMARY}

The status of three major tasks are reported below.

Engineering Characteristics of Optimized Cement-Based Mixtures Containing FBC Spent Bed

Nine different matrix proportions containing type $V$ Portland cement, FBC sperit bed, PFC fly ash, natural fine aggregate (sand) and limerock coarse aggregate were considered for this task. The workability, expressed in terms of slump, of all mixtures were measured to be $4 \pm \frac{1}{4}$. Test results indicated that the accumulated bleeding water, expressed as a percentage of the net mixing water contained within the test specimens, of all mixes were below 18 . The air content of fresh concretes were fairly similar to each other and ranged from 1 to 1.58. The final time of setting improved as the sand and cement content of the matrix increased. They ranged from 8 to 38 hours. The early shrinkage of FBC spent bed concrete mixes decreased with the increase of cement content and increased as the sand content of the matrix improved. This is easily explained since higher mixing water alleviates the loss of water by evaporation through concrete's surface and, thus, results in lower plastic shrinkage. The 7-day sealed compressive strength varied from 1150 to 2100 psi.

Engineering Characteristics of Optimized Cement-Based Mixtures Containing FBC Fly Ash

Matrix constituents for this task consisted of Portland cement type I and V, FBC fly ash, natural sand and limestone coarse aggregate. Twelve different mix proportions were selected and laboratory specimens are being fabricated and tested. The evaluation methodology is similar to the one reported for the task above. Test results will be discussed on next quarterly reports.

Engineering Characteristics of Roller Compacted Non-Cement FBC Mixes

The third and final phase of this investigation involves evaluation of the optimized roller compacted non-cement concrete mixes. Based on the testing results obtained from Phases I and II, six different matrix proportions containing FBC spent bed, PFC fly ash, natural river sand, and limestone coarse aggregates, were selected. The 28-day sealed compressive strengths varied from 2200 to 3850 psi, whereas the 28-day sealed split-tensile resistance were between 300 to 420 psi. At the end of ninety days curing, the compressive strength of the tested specimens were improved to nearly 4000 to $6200 \mathrm{psi}$ when tested under identical conditions. Clearly, these respectable strength re- 
sults suggest the potential use of the proposed mixes, as a suitable paving material, for a variety of road construction applications.

To date, the expansion strain of the optimized mixes, obtained under soaked curing, are between 1 to 28 . These values are much higher than the equivalent samples tested under sealed conditions. The expansion strain of the mixes containing natural sand are consistently superior to those with no natural sand. Tests on flexural strength, modulus of elasticity, abrasion resistance and sulfate durability are on-going and will be discussed on next quarterly report.

Nomenclature

FBC=Fluidized bed combustion

$\mathrm{PFC}=\mathrm{Pulverized}$ fuel combustion

\section{DISCLAIMER}

This report was prepared as an account of work sponsored by an agency of the United States Government. Neither the United States Government nor any agency thereof, nor any of their employees, makes any warranty, express or implied, or assumes any legal liability or responsibility for the accuracy, completeness, or usefulness of any information, apparatus, product, or process disclosed, or represents that its use would not infringe privately owned rights. Reference herein to any specific commercial product, process, or service by trade name, trademark, manufacturer, or otherwise does not necessarily constitute or imply its endorsement, recom. mendation, or favoring by the United States Government or any agency thereof. The views and opinions of authors expressed herein do not necessarily state or reflect those of the
United States Government or any agency thereof. 


\section{OBJECTIVES}

This research project is designed to examine the extent to which FBC by-products can be used in portland cement-based and non-Portland cement-based mixtures. This investigation will focus on the properties of FBC residues derived from burning of Illinois high-sulfur coal. The initial focus of this investigation is the evaluation of physico-chemical properties and preconditioning studies of the FBC fly ash and spent bed. The second phase of this investigation is divided into two tasks, namely: the sulfate durability of Portland cement concrete containing FBC residues (fly ash and spent bed) and engineering properties of rollercompacted non cement mixes.

Due to presence of calcium sulfate in FBC by-products and, thus, possible formation of ettringite, the first task of the second phase concentrates on the long-term durability regarding the internal sulfate attack of the portland cement-based mixtures containing FBC fly ash and spent bed. Once the maximum permissible FBC by-products in cementbased mixtures is established, various mix proportions corresponding to different strength levels will be subjected to a comprehensive testing program to identify their short and long-term engineering characteristics.

The second task of this investigation examines the engineering characteristics of roller compacted non-cement FBC residues for possible applications in pavement construction.

During this reporting period, laboratory specimens relevant to the final phase of this research program; engineering characteristics of the optimized FBC spent bed and $f l y$ ash concretes (Task I), and engineering properties of the optimized roller compacted non-cement FBC mixes (Task II); were fabricated. Tests on fresh and hardened properties are ongoing.

\section{INTRODUCTION AND BACKGROUND}

In an attempt to reduce the potential hazards of acid rain and enhance the quality of life in the state of Illinois, coal-fired plants burning high-sulfur Illinois coal are adopting fluidized bed combustion process. FBC results in the production of vast quantities of by-product wastes which have different physico-chenical characteristics than those generated by the conventional coal-burning processes. It is the thrust of this research project to scientifically investigate the feasibility of utilizing FBC residues as binder and/or filler aggregates in a variety of construction applications. 
In summary, this project would have a dual purpose aimed at enhancing the economic and industrial well-being of the State by developing cost-effective construction materials while using by-product wastes, generated by burning highsulfur coal, which would otherwise end up in landfills causing adverse environmental and economical problems.

\section{EXPERIMENTAL PROCEDURES}

Fresh properties were obtained using ASTM Cl43 (air content), ASTM C232 (bleeding), ASTM C403 (time of setting), ASTM C827 (early shrinkage) and ASTM Cl064 (temperature). Hardened characteristics were evaluated based on ASTM C39 (density and compressive strength), ASTM C496 (splittensile strength), ASTM C78 (flexural strength), ASTM C469 (static modulus of elasticity), ASTM C157 (drying shrinkage and expansion), ASTM C806 (sulfate durability), and ASTM C779 (abrasion resistance). The laboratory specimens for the roller-compacted non-cement mixes were prepared using ASTM D1557.

\section{RESULTS AND DISCUSSION}

Engineering Characteristics of Optimized Cement-Based Mixtures Containing FBC Spent Bed

Nine different matrix proportions containing type $V$ Portland cement, FBC spent bed, PFC fly ash, natural fine aggregate (sand) and limerock coarse aggregate were considered for this task (see Table 1). The workability, expressed in terms of slump, of all mixtures were measured to be $4 \pm \frac{1}{4}$. Test results indicated that the accumulated bleeding water, expressed as a percentage of the net mixing water contained within the test specimens, of all mixes were below 18. The air content of fresh concretes were fairly similar to each other and ranged from 1 to 1.58 . The final time of setting improved as the sand and cement content of the matrix increased. They ranged from 8 to 38 hours. The early shrinkage of FBC spent bed concrete mixes decreased with the increase of cement content and increased as the sand content of the matrix improved. This is easily explained since higher mixing water alleviates the loss of water by evaporation through concrete's surface and, thus, results in lower plastic shrinkage. The 7-day sealed compressive strength varied from 1150 to 2100 psi.

Engineering Characteristics of Optimized Cement-Based Mixtures Containing FBC Fly Ash

Matrix constituents for this task consisted of Portland cement type $I$ and $V, F B C$ fly ash, natural sand and limestone coarse aggregate. Twelve different mix proportions were 
selected as shown in Table 2, and laboratory specimens are being fabricated and tested. The evaluation methodology is similar to the one reported for the task above. Test results will be discussed on next quarterly reports.

Engineering Characteristics of Roller Compacted Non-Cement FBC Mixes

The third and final phase of this investigation involves evaluation of the optimized roller compacted non-cement concrete mixes. Based on the testing results obtained from Phases I and II, six different matrix proportions containing FBC spent bed, PFC fly ash, natural river sand, and limestone coarse aggregates, as shown in Table 3, were selected. The 28-day sealed compressive strengths varied from 2200 to 3850 psi, whereas the 28 -day sealed splittensile resistance were between 300 to $420 \mathrm{psi}$. At the end of ninety days curing, the compressive strength of the tested specimens were improved to nearly 4000 to 6200 psi when tested under identical conditions. Clearly, these respectable strength results suggest the potential use of the proposed mixes, as a suitable paving material, for a variety of road construction applications.

To date, the expansion strain of the optimized mixes, obtained under soaked curing, are between 1 to $2 \%$. These values are much higher than the equivalent samples tested under sealed conditions. The expansion strain of the mixes containing natural sand are consistently superior to those with no natural sand. Tests on flexural strength, modulus of elasticity, abrasion resistance and sulfate durability are on-going and will be discussed on next quarterly report.

Nomenclature

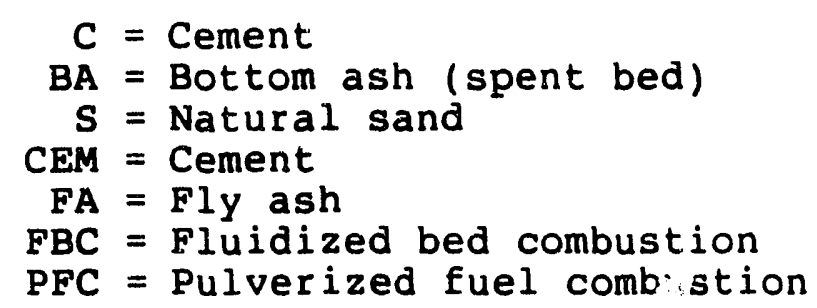




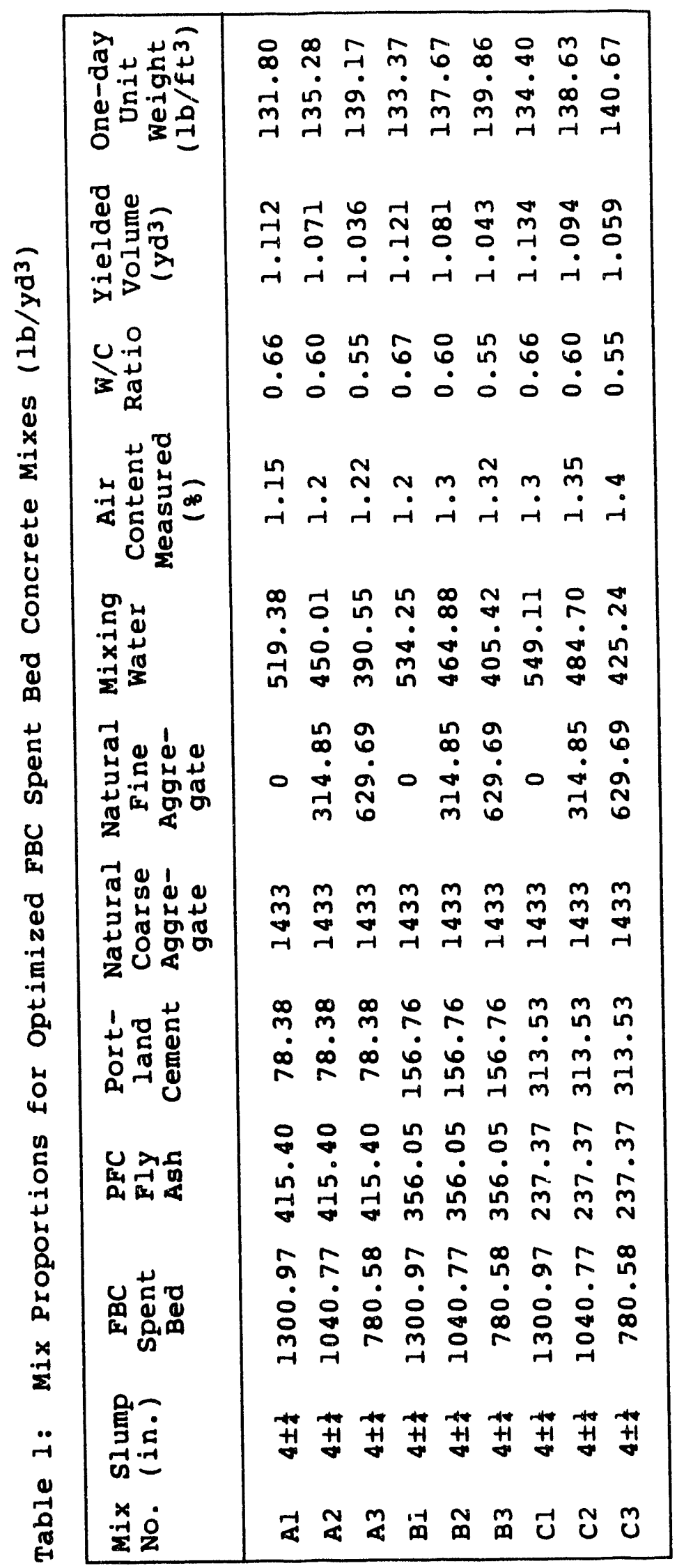




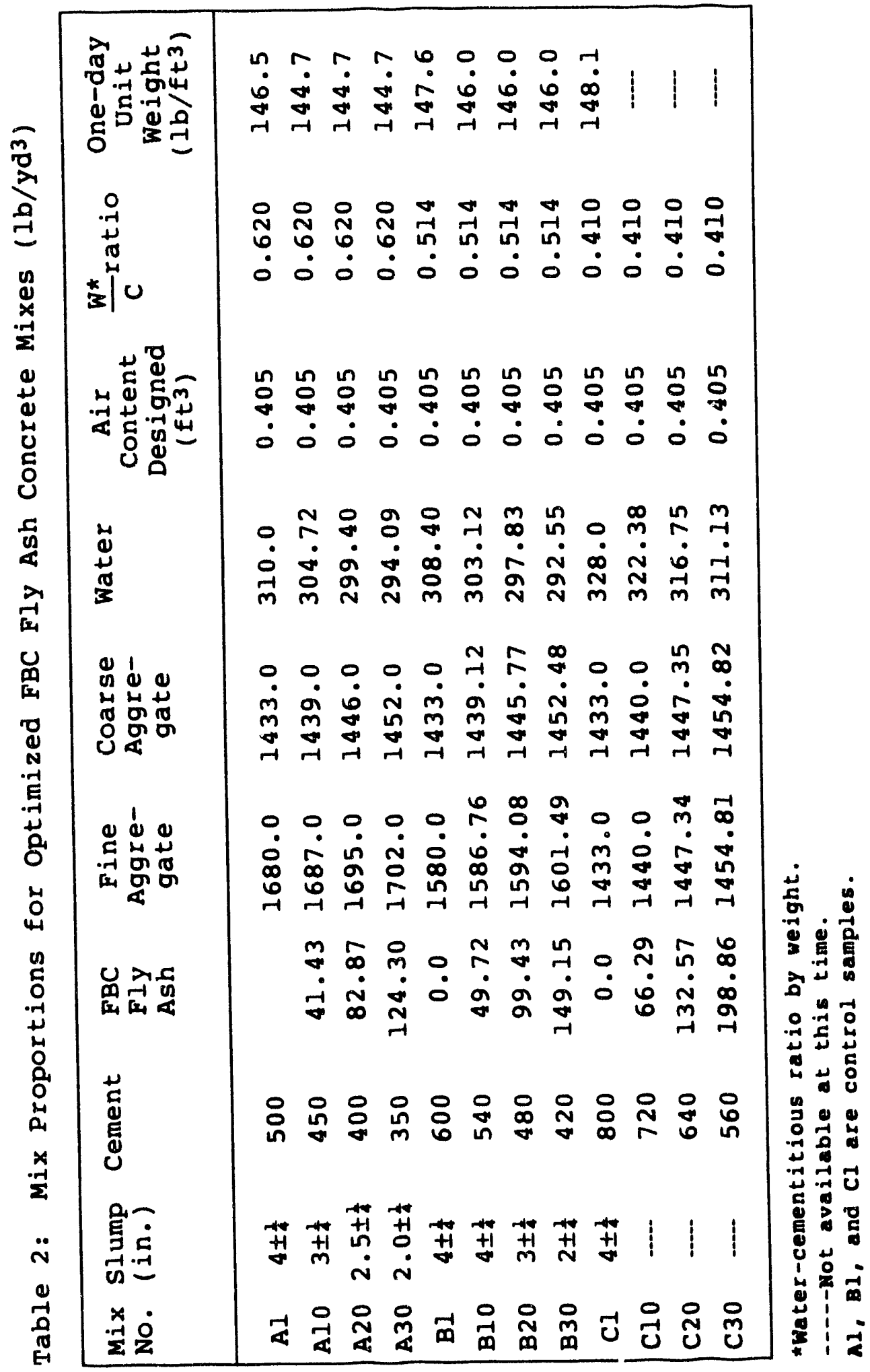


Table 3: Mix Proportions for Optimized Roller-Compacted Non-Cement FBC Mixes (Phase III)

\begin{tabular}{|ccccc|}
\hline $\begin{array}{c}\text { FA/SB } \\
\text { Ratio* }\end{array}$ & $\begin{array}{c}\text { Percent } \\
\text { AFC Fly } \\
\text { Ash } \\
(\text { FA) }\end{array}$ & $\begin{array}{c}\text { Percent } \\
\text { FBC Spent } \\
\text { Bed } \\
(\text { SB })^{\star}\end{array}$ & $\begin{array}{c}\text { Percent } \\
\text { Natural } \\
\text { Sand } \\
(\mathrm{S})\end{array}$ & $\begin{array}{c}\text { Percent } \\
\text { Limestone } \\
\text { Aggregate } \\
(\text { CA })\end{array}$ \\
\hline $1: 4$ & 9.0 & 21.6 & 14.4 & 55.0 \\
$1: 2$ & 15.0 & 18.0 & 12.0 & 55.0 \\
$1: 1$ & 22.5 & 13.5 & 9.0 & 55.0 \\
\hline $1: 4$ & 8.0 & 32.0 & 0.0 & 60.0 \\
$1: 2$ & 13.33 & 26.67 & 0.0 & 60.0 \\
$1: 1$ & 20.0 & 20.0 & 0.0 & 60.0 \\
\hline
\end{tabular}

*Weight ratio.

$\star \star 8$ by weight of total dry solid. 

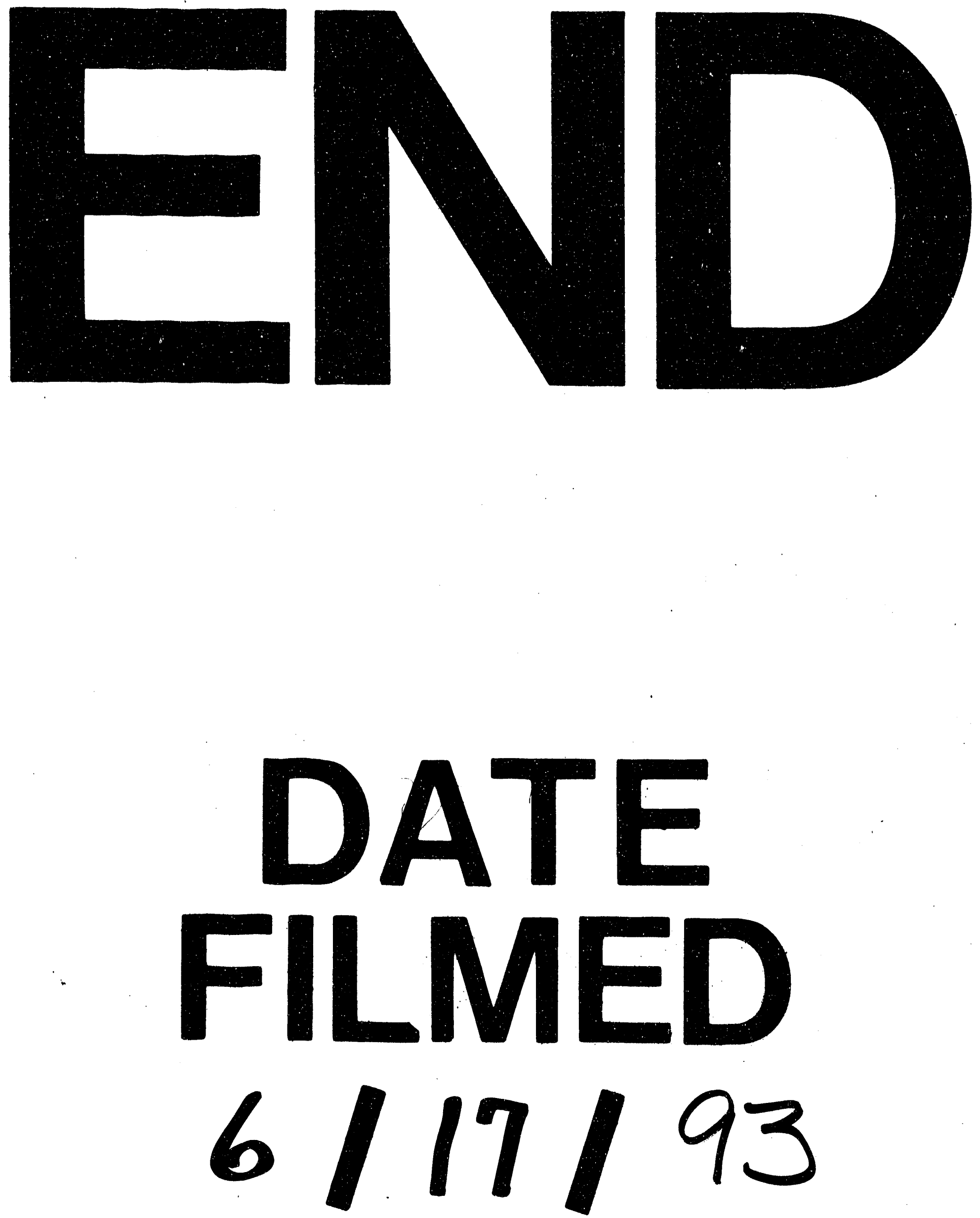
